\title{
Heat Transfer in a Square Porous Cavity With Partial Heating and Cooling for Opposite Vertical Walls
}

\author{
Muyassar E. Ismaeel \\ Assistant Lecturer \\ Department of Mechanical Engineering/University of Mosul
}

\begin{abstract}
Numerical study has been conducted to investigate natural convection heat transfer in a square porous cavity with partial active vertical walls. The left vertical side wall is partially heated and the right side wall is partially cooled. Depending on the positions of the hot and cold parts, nine cases have been considered in this investigation. Flow and heat transfer characteristics for all cases have been studied for range of Rayleigh number $50 \leq$ Ram $\leq 500$. The governing equations are solved numerically with aid of the finite difference technique and Gauss - Siedel method. Numerical results showed that there are significant changes in the flow and temperature fields and the rate of heat transfer due to the change of the positions of hot-cold parts. Also, they showed that the maximum heat transfer occurs for the Lower-Upper arrangement, while the minimum heat transfer occurs for the Upper-Lower arrangement. A correlation between $\overline{\mathrm{Nu}}$ and Ram proposed for each one of the nine cases.
\end{abstract}

Keywords: Natural Convection, Porous Cavity, Partial Heating.

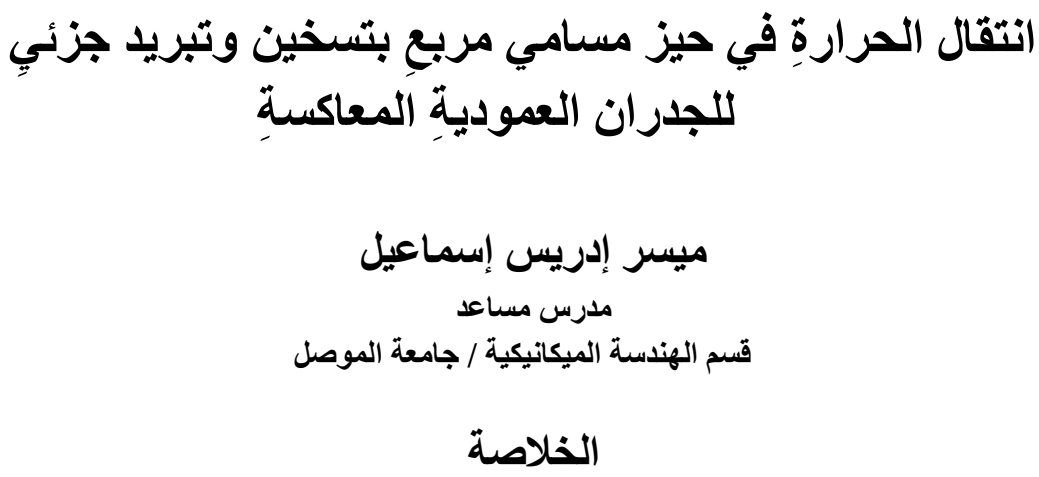

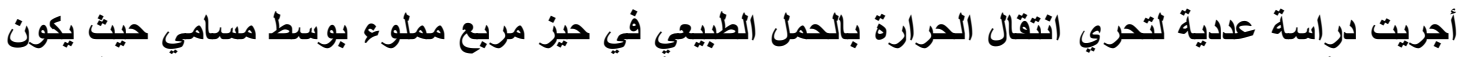

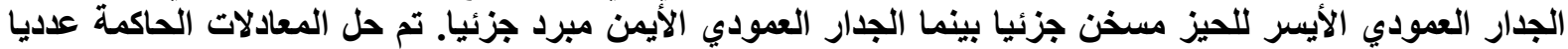

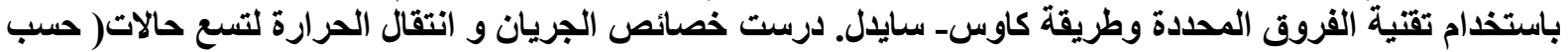

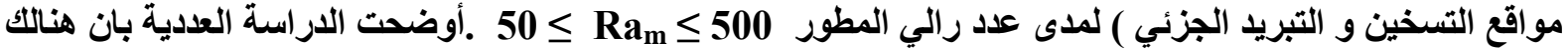

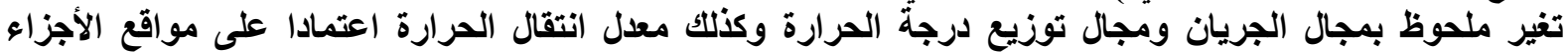

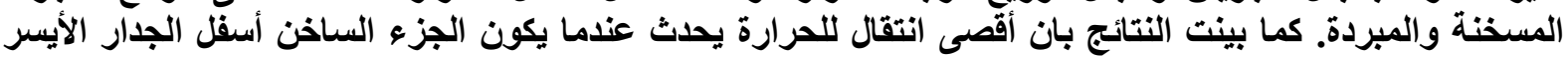

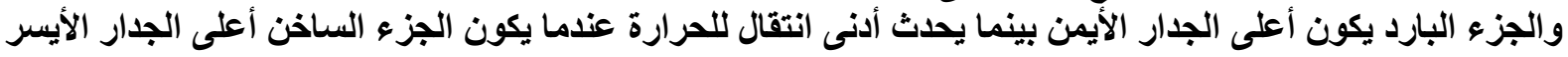
و الجزء البارد يكون أسفل الجدار الأيمن. وقد اقترحت معادلة ارتباط بين Nu و Ra 


\section{NOMENCLATURE}

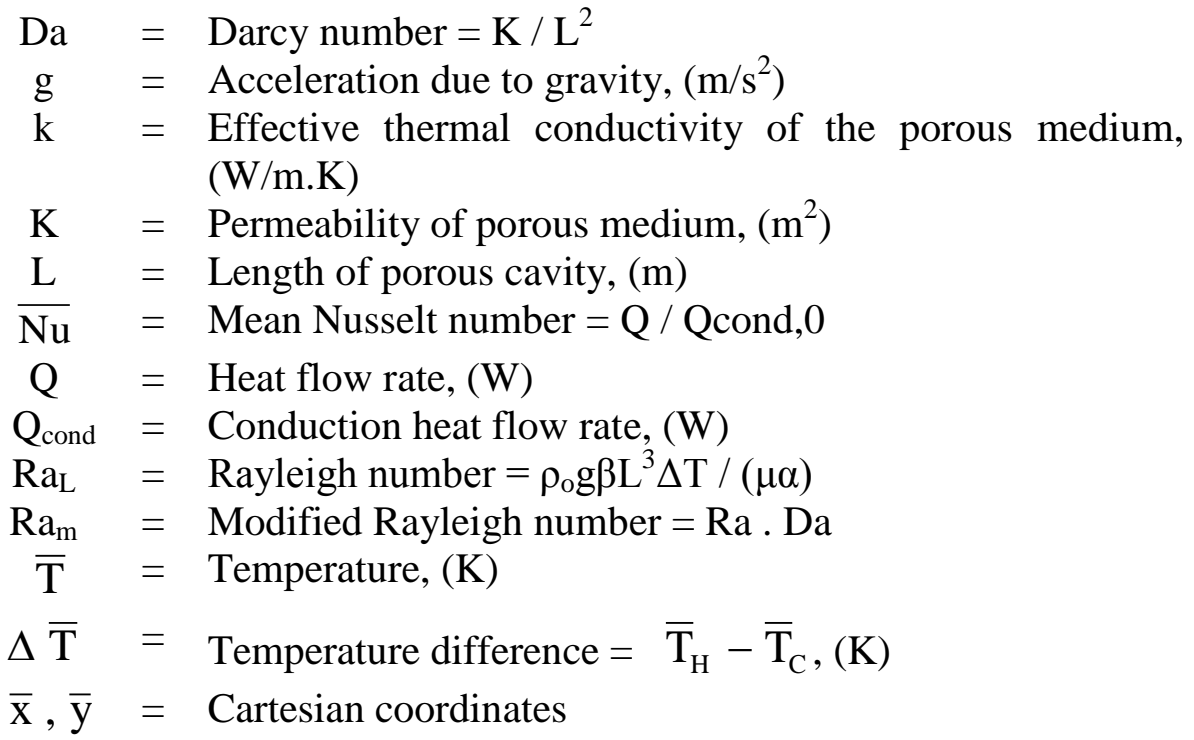

Greek Symbols

$\beta=$ Thermal coefficient of volumetric expansion, $\left(\mathrm{K}^{-1}\right)$

$\mu \quad=$ Dynamic viscosity, $(\mathrm{kg} / \mathrm{m} . \mathrm{s})$

$\rho=$ Density, $\left(\mathrm{kg} / \mathrm{m}^{3}\right)$

$\bar{\Psi}=$ Stream function, $\left(\mathrm{m}^{2} / \mathrm{s}\right)$

Subscript

$\mathrm{C}=$ Cold wall

$\mathrm{H}=$ Hot wall

$\mathrm{o}=$ Reference point 


\section{Introduction}

The importance of natural convection heat transfer in porous media stems from the fact that it has so many applications in engineering and practice such as geothermal energy, energy systems storage, compact heat exchangers, buildings insulation, solar collectors, nuclear engineering and cooling of radioactive waste containers, etc.. [1,2].

During the past decades, many researches have been done for natural convection heat transfer in a rectangular or square enclosure filled with a fluid saturated porous medium differentially heated from the vertical walls while the horizontal walls are insulated. Bejan and Poulkakos in 1984 [3] described the heat transfer and fluid flow through a confined porous layer heated and cold along one of the vertical side walls. They studied two cases: the first case is when the heating-side effect is positioned above the cooling-side effect. They showed that natural circulation is either one of the incomplete vertical penetration, or one of incomplete horizontal penetration. The second case is when the heated portion of the side wall is located below the cooled portion. In this case the flow spreads throughout the porous medium. Lai and Kulacki in 1988 [1] studied numerically the natural convection in a twodimensional layered porous cavity heated from the side wall. They emphasized on the effects caused by the sub-layer thickness ratio, permeability contrast and non-uniform conductivity in a system comprising two layers. A wide range of these parameters have been covered in their calculation. It has been observed that the heat transfer and fluid flow are affected with these parameters. Varol et. al. in 2008 [2] performed an estimation of thermal and flow field due to convection using SVM (support vector machines, a soft programming techniques) in porous cavity with discrete heat sources. They used three isothermal heaters to heat the left vertical wall, while the right vertical wall is kept at a lower temperature. They observed that SVM was a useful technique in estimating streamlines and isotherms. Varol et. al. in 2009 [4] conducted numerical study to investigate the steady free convection flow in a twodimensional right-angle trapezoidal enclosure filled with a fluid saturated porous medium. In their study, the left vertical wall of the cavity was heated, the inclined wall was partially cooled and the remaining walls were insulated. Three different locations of the cooler were investigated. The effect of modified Rayleigh number and aspect Ratio on heat transfer and fluid flow are also presented. It is noticed that there exist significant changes in the flow and temperature fields as compared with those of a differentially heated square porous cavity.

In the case of no-porous media, Fredrick et. al. in 1989 [5] numerically investigated the natural convection of air in a square cavities with half-active and half-insulated vertical walls for different values of Rayleigh number. Aydin and Yang in 2000 [6] numerically investigated the natural convection of air in a two-dimensional, rectangular enclosure with localized heating from below and symmetrical cooling from the sides. Erbay L.B. et. al. in 2004 [7] numerically investigated the entropy generation in a square enclosure with partial heating, from a vertical lateral walls. Nithyadevi et. al. in 2007 [8] performed numerical investigation of the effect of the aspect ratio on the natural convection of a fluid contained in a rectangular cavity with partially thermally active side walls. Koca et. al. in 2007 [9] numerically analyzed the effect of Prandtl number on natural convection heat transfer and fluid flow in triangular enclosures with localized heating. Oztop et. al. in 2008 [10] carried out a numerical study on heat transfer and fluid flow due to buoyancy forces in a partially heated enclosure using nanofluids. 
To the best Knowledge of the author, there is no study on the effect of partially thermally active side walls in a rectangular cavity containing porous media. Thus, the objective of the present study is to document the heat transfer effect with the presence of partial heating and cooling on the sides of enclosure containing porous media.

\section{Physical Modeling}

The physical situation of the problem under study with the coordinate system and boundary conditions is depicted in Figure (1), it represent one of the nine cases under study. It is a two-dimensional square cavity of length (L) filled with fluid saturated porous media. The left-hand side wall is partially heated and maintained at uniform temperature $\left(\overline{\mathrm{T}}_{\mathrm{H}}\right)$, while the right-hand side is partially cooled and maintained at uniform temperature $\left(\bar{T}_{C}\right)$. The reminder parts of walls are insulated. The length of the active parts is half the length of corresponding wall $(\mathrm{L} / 2)$. The position of the hot part is changed from top to bottom (top, Centre, and bottom), while the cold part is changed from bottom to top (bottom, Centre, and top). Depending on the location of the hot-cold parts, nine situations are studied in this investigation.

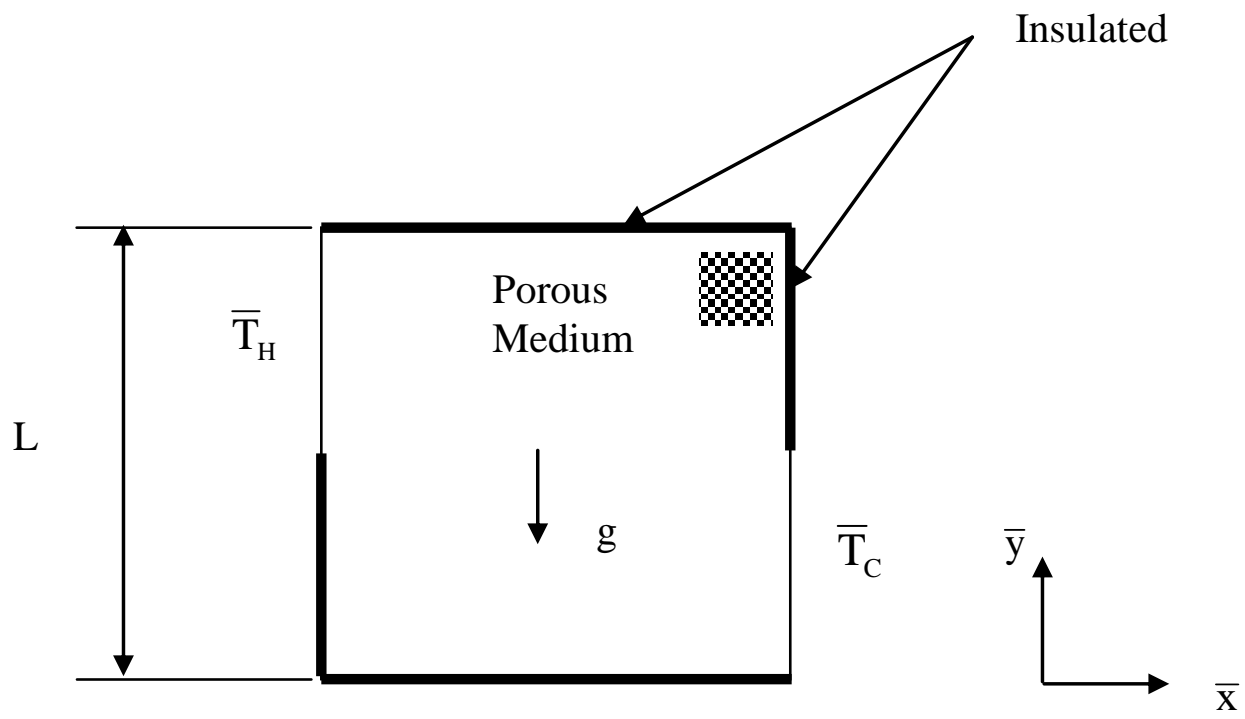

Figure (1) Physical situation of the problem. It represents one of nine cases under study,

Upper-Lower active walls.

(The hot portion on the upper left side - The cold portion on the lower right side)

\section{Equations}

In this investigation, some assumptions were made to write governing equations such as that the porous matrix is rigid and isotropic in thermal conductivity, the porosity and permeability of the homogeneous porous medium are uniform, the fluid is assumed as Newtonian, incompressible and the flow is laminar. The fluid and solid properties are also constant except the density of fluid which changes with the temperature that is Boussinesq approximation applied. Finally, it is assumed that the fluid and porous medium are in thermal equilibrium and the fluid motion is described by Darcy's law. 
According to the above descriptions and assumptions of the problem, the governing equations in terms of the stream function $\bar{\Psi}$ and $\overline{\mathrm{T}}$ temperature for two-dimension and steady state condition are [1]:

$\frac{\partial^{2} \bar{\Psi}}{\partial \overline{\mathrm{x}}^{2}}+\frac{\partial^{2} \bar{\Psi}}{\partial \overline{\mathrm{y}}^{2}}=-\frac{\mathrm{K} \rho_{\mathrm{o}} \beta \mathrm{g}}{\mu} \frac{\partial \overline{\mathrm{T}}}{\partial \overline{\mathrm{x}}}$
$\frac{\partial \bar{\Psi}}{\partial \overline{\mathrm{y}}} \frac{\partial \overline{\mathrm{T}}}{\partial \overline{\mathrm{x}}}-\frac{\partial \bar{\Psi}}{\partial \overline{\mathrm{x}}} \frac{\partial \overline{\mathrm{T}}}{\partial \overline{\mathrm{y}}}=\alpha_{\mathrm{m}}\left[\frac{\partial^{2} \overline{\mathrm{T}}}{\partial \overline{\mathrm{x}}^{2}}+\frac{\partial^{2} \overline{\mathrm{T}}}{\partial \overline{\mathrm{y}}^{2}}\right]$

With the non-dimensional variables defined below:

$\mathrm{x}, \mathrm{y}=\frac{\overline{\mathrm{x}}, \overline{\mathrm{y}}}{\mathrm{L}} \quad, \quad \mathrm{u}, \mathrm{v}=\frac{\overline{\mathrm{u}}, \overline{\mathrm{v}}}{\mathrm{L}} \quad, \quad \Psi=\frac{\bar{\Psi}}{\alpha_{\mathrm{m}}} \quad$ and $\quad \mathrm{T}=\frac{\overline{\mathrm{T}}-\overline{\mathrm{T}}_{\mathrm{C}}}{\overline{\mathrm{T}}_{\mathrm{H}}-\overline{\mathrm{T}}_{\mathrm{C}}}$

Equations (1) and (2) can be written in non-dimensional form as follow:

$\frac{\partial^{2} \Psi}{\partial x^{2}}+\frac{\partial^{2} \Psi}{\partial y^{2}}=-\operatorname{Ra}_{m} \frac{\partial T}{\partial x}$

$\frac{\partial \Psi}{\partial \mathrm{y}} \frac{\partial \mathrm{T}}{\partial \mathrm{x}}-\frac{\partial \Psi}{\partial \mathrm{x}} \frac{\partial \mathrm{T}}{\partial \mathrm{y}}=\frac{\partial^{2} \mathrm{~T}}{\partial \mathrm{x}^{2}}+\frac{\partial^{2} \mathrm{~T}}{\partial \mathrm{y}^{2}}$

Where $\operatorname{Ra}_{m}=\frac{\operatorname{Kg} \beta \Delta \overline{\mathrm{T}} \mathrm{L}_{\mathrm{o}}}{\mathrm{k} \mu}$ is the modified Rayleigh number.

The non-dimensional boundary conditions for the considered model are:

$\Psi=0$ on all solid boundaries

$\frac{\partial \mathrm{T}}{\partial \mathrm{n}}=0$ on the adiabatic wall

$\mathrm{T}=1$

on the hot wall

$\mathrm{T}=0$

on the hot wall

\}

The average Nusselt number is calculated on the hot and cold walls as follows:

$\overline{\mathrm{Nu}}=\int \frac{\partial \mathrm{T}}{\partial \mathrm{y}} \mathrm{dx}$

\section{Numerical Solution}

A FORTRAN computer program utilizing finite difference method is used to solve numerically the non-dimensional governing equations (equations (3) and (4)) with the boundary conditions (equation (6)). The region of interest was covered with $m$ vertical and $n$ horizontal uniformly spaced grid lines. An iterative process is employed to find the stream function and temperature fields. The process is repeated until the following convergence criterion is satisfied

$\sum\left|\mathrm{TN}_{\mathrm{ij}}-\mathrm{T}_{\mathrm{ij}}\right| \leq 10^{-4}$ 
The Nusselt number $(\overline{\mathrm{Nu}})$ values calculated at different grid sizes. It is noticed that the difference in $(\overline{\mathrm{Nu}})$ values between grid size $(71 \mathrm{x} \quad 71)$ and $(81 \times 81)$ is approximately less than $(0.55 \%)$ for all cases at $\mathrm{Ra}_{\mathrm{m}}=500$. Another test is made to check the rate of heat transfer at the active walls. It is found that, in some cases, there is an unacceptable difference between them. For these cases, a grid size $(251 \times 251)$ has been used to reduce the difference less than $1.9 \%$.

To check the validity of the present computer program, it is run with conditions similar to that of previous work. Tables (1 and 2) list a comparison with the previous work. The results show good agreement. Depending upon this comparison, the present code is valid to study the present problem.

Table (1) Comparison of the mean Nusselt number at $\mathrm{Ra}_{\mathrm{m}}=1000$ [12].

\begin{tabular}{|l|c|}
\hline Paper & $\overline{\mathrm{Nu}}$ \\
\hline \hline Bejan & \\
\hline Baytas and Pop & 15.800 \\
\hline Said and Pop & 14.060 \\
\hline \hline Varol et al. & 13.726 \\
\hline Present work & 13.564 \\
\hline
\end{tabular}

Table (2) Comparison of the mean Nusselt number.

\begin{tabular}{||c||c|c|c|c||}
\hline \hline \multirow{2}{*}{$\mathbf{R a}_{\mathbf{m}}$} & \multicolumn{4}{|c||}{$\mathrm{Nu}$} \\
\cline { 2 - 5 } & Chan [13] & Bejan [14] & Bejan and Tien [15] & Present work \\
\hline \hline $\mathbf{5 0}$ & 2.1 & 1.897 & 2.12 & $\mathbf{2 . 0 1 4}$ \\
\hline \hline $\mathbf{1 0 0}$ & 3.54 & 3.433 & 3.25 & $\mathbf{3 . 2 5 7}$ \\
\hline
\end{tabular}

\section{Results and discussion}

This investigation is performed to study numerically the steady state laminar natural convection heat transfer in a square porous cavity with different locations of partial thermally active vertical walls and modified Rayleigh numbers $(50-500)$.

The flow field and isotherms for the case of Upper - Lower thermally active location with different values of Rayleigh number $\left(\mathrm{Ra}_{\mathrm{m}}\right)$ are shown in Figure (2). It is clear that, for $\mathrm{Ra}_{\mathrm{m}}=50$, a single cellular stream function configuration with $(\Psi \max =-1.4)$ is obtained and the temperature distribution lines near the vertical sides are almost parallel to active part because of the domination convection mode. It is very clear from the absolute values of stream function as demonstrated in Figure (2), the increasing of Rayleigh number lead to the increase in the strength of convection mode ( e.g. $\Psi_{\max }=-4.14$ at $\mathrm{Ra}_{\mathrm{m}}=500$ ) as a result of increasing the buoyancy force. Also, a trend to form a two flow cell is noticed with increasing Rayleigh number. The centre of each cell shifted toward the adjacent thermally active portion. On the other hand, the temperature distribution is modified to be parallel to the horizontal wall at the Centre of the cavity. Changing the location of the hot portion affects the configuration of the isograms. Figure (3) represents the streamlines and isotherms for the case of Central - Lower thermally active location. It is obvious that the formation of two 
flow cells needs higher values of Raleigh number in comparison with that for the Upper Lower thermally active location. Furthermore, the temperature distribution covers about 3/4 of the cavity at high Rayleigh number. In contrast, the flow filed for the case of lower Lower thermally active location, Figure (4), is a one cell and the temperature distribution occupies the lower half of the cavity.

When the cold portion is held fixed at the centre of the right wall and the hot portion on the left side and its position to changed from top to bottom, different isograms is obtained. Figure $(5-7)$ shows the streamlines and isotherm for the three combinations at Rayleigh numbers 400 and 500.

$\mathrm{Ra}_{\mathrm{m}}=50$
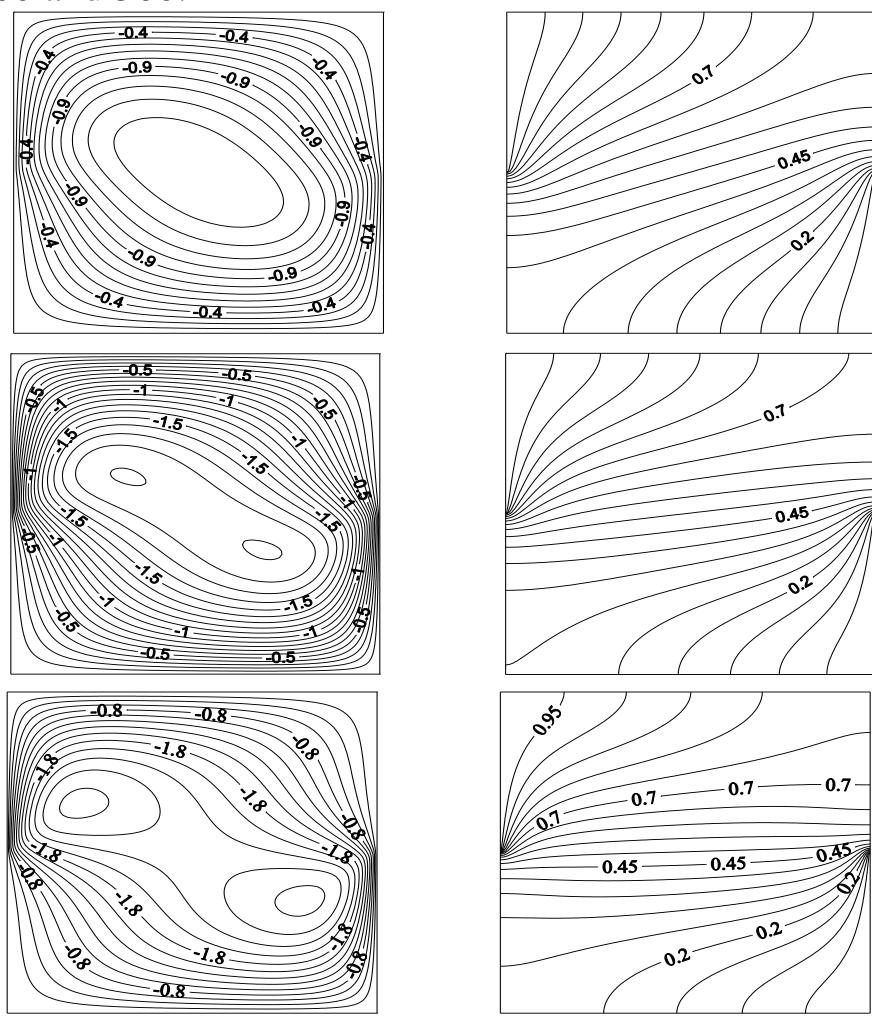

$\mathrm{Ra}_{\mathrm{m}}=100$

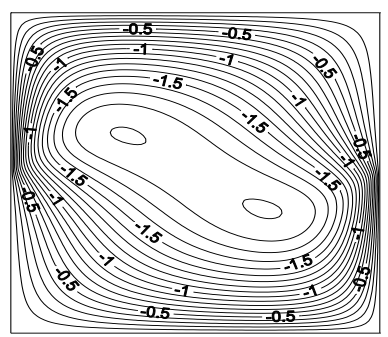

$\mathrm{Ra}_{\mathrm{m}}=200$
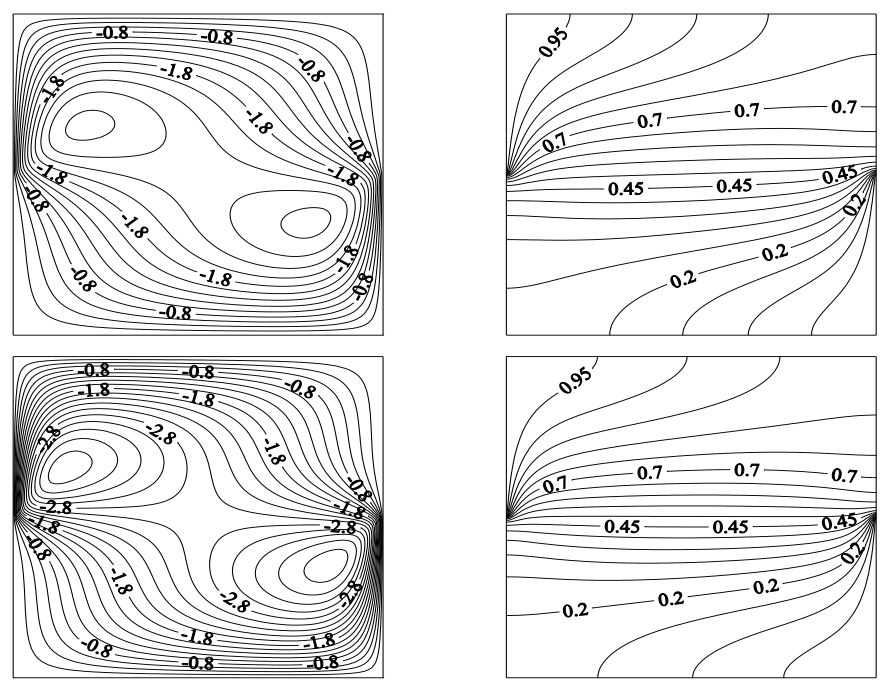

$\mathrm{Ra}_{\mathrm{m}}=400$
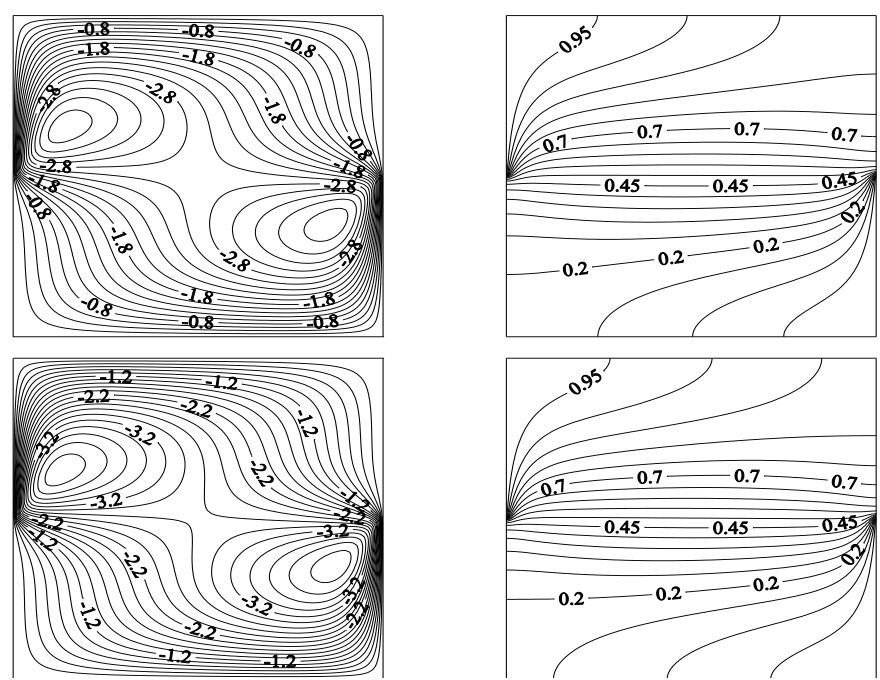

Figure (2) Effect of Rayleigh number for the case (Upper - Lower). (The hot portion on the upper left side - The cold portion on the lower right side) 
$\mathrm{Ra}_{\mathrm{m}}=50$

$\mathrm{Ra}_{\mathrm{m}}=100$
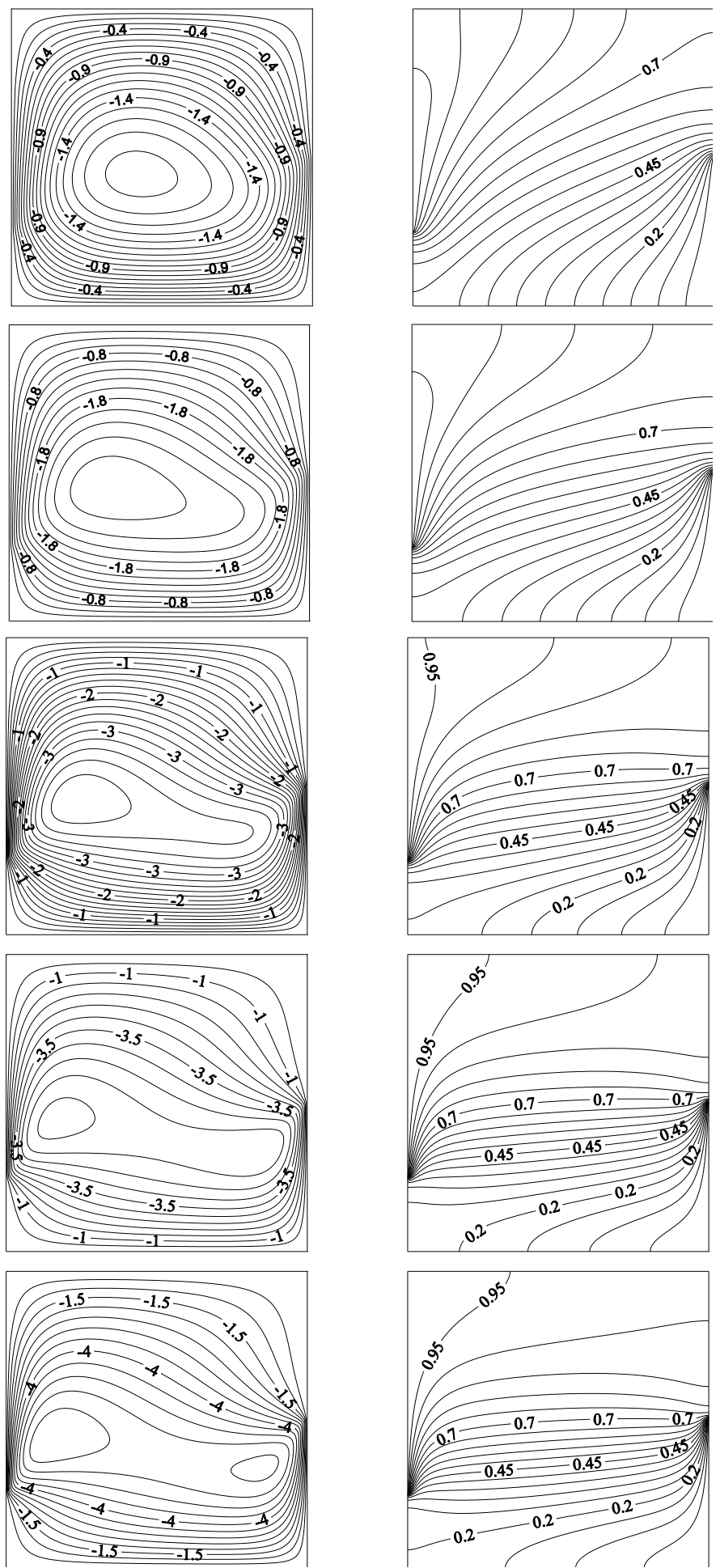

Figure (3) Effect of Rayleigh number for the case ( Central - Lower ).

(The hot portion at the Centre of left side - The cold portion on the lower right side) 
$\mathrm{Ra}_{\mathrm{m}}=50$

$\mathrm{Ra}_{\mathrm{m}}=100$

$\mathrm{Ra}_{\mathrm{m}}=200$

$\mathrm{Ra}_{\mathrm{m}}=400$

$\mathrm{Ra}_{\mathrm{m}}=500$
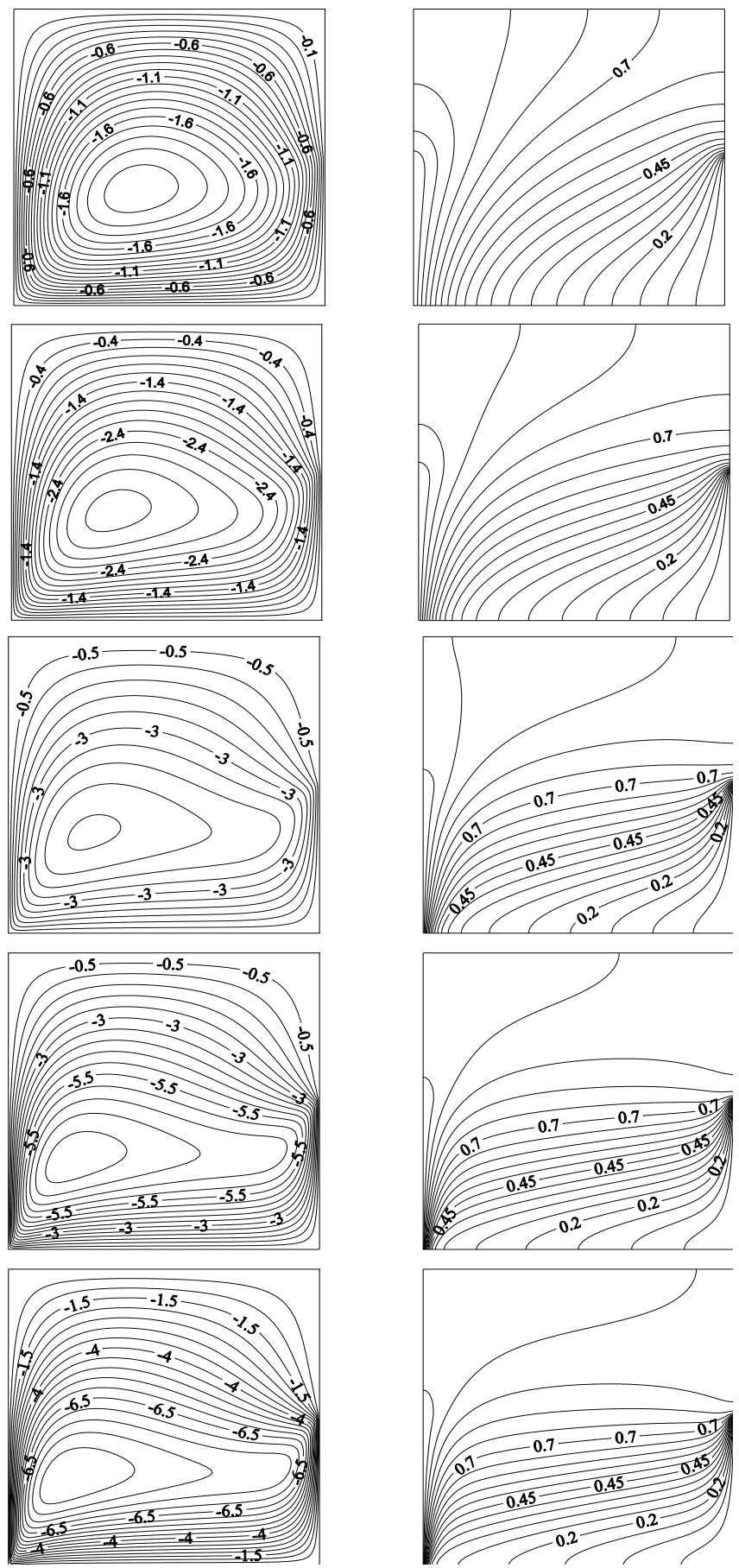

Figure (4) Effect of Rayleigh number for the case (Lower - Lower ).

(The hot portion on the lower left side - The cold portion on the lower right side)

Figure (5) shows the case of Upper - Central thermally active location. It is clear that the strength of convection increases with increasing the modified Rayleigh number, e.g. $\Psi_{\max }=-5.74$ and $\Psi_{\max }=-6.46$ at $\mathrm{Ra}_{\mathrm{m}}=400$ and 500 respectively. In addition, the temperature distribution and flow filed occupies the upper part of the cavity. Furthermore, there is a chance for the flow to form two cells and the centre of each cell will be directed toward the nearest active portion. 
On the other hand, the case of Central - Central thermally active location in Figure (6) shows a single flow cell occupying the whole cavity and the flow tries to be divided into two cells as shown.

The case of Lower - Central thermally active location in Figure (7) shows also a single flow cell with the centre going to the hot active portion. Here, the flow is stressed at the lower part of the cavity.

The final case is represented in Figure (8) for Rayleigh number 500. In this case, the cold portion on the right wall is located at the upper half of the wall and the hot portion on the left wall is moved from top to bottom. Figure $(8-a$ and $b)$ illustrates the cases of Upper - Upper and Central - Upper thermally active location which are the mirror image of the cases of Lower - Lower and Lower - Central thermally active location respectively. Figure $(8$ - c) depicted the case of Lower - Upper thermally active location. The flow filed is comprised of one cell and cover the whole cavity.

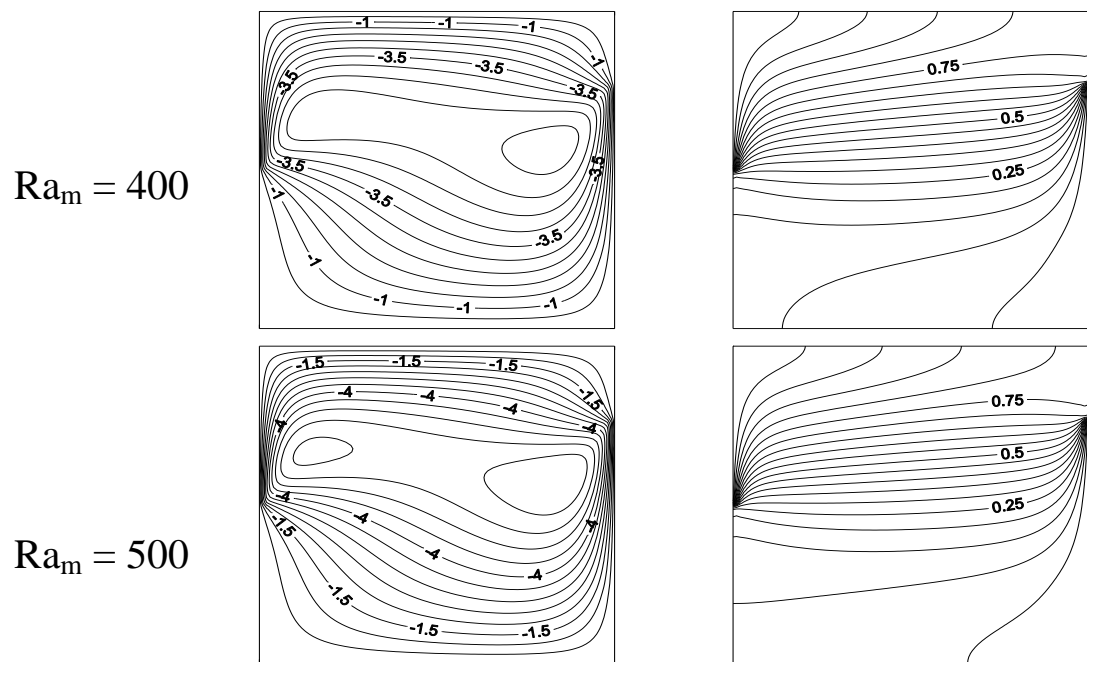

Figure (5) Effect of Rayleigh number for the case (Upper - Central).
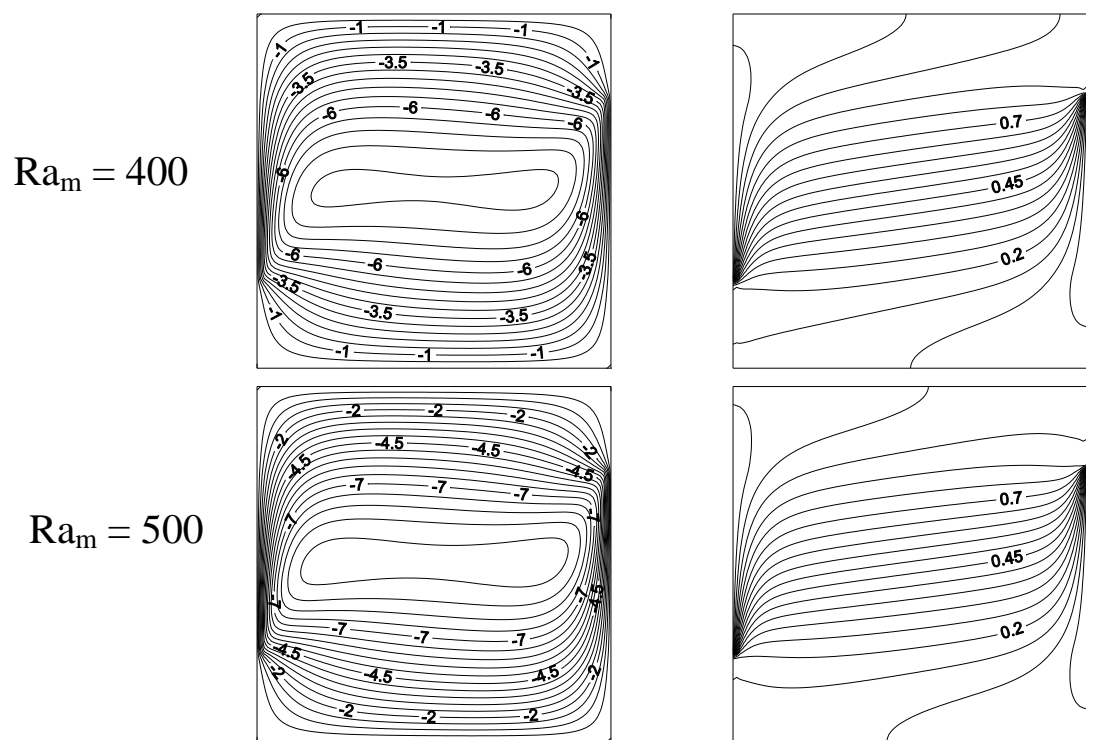

Figure (6) Effect of Rayleigh number for the case (Central - Central). 
$\mathrm{Ra}_{\mathrm{m}}=400$

$\mathrm{Ra}_{\mathrm{m}}=500$
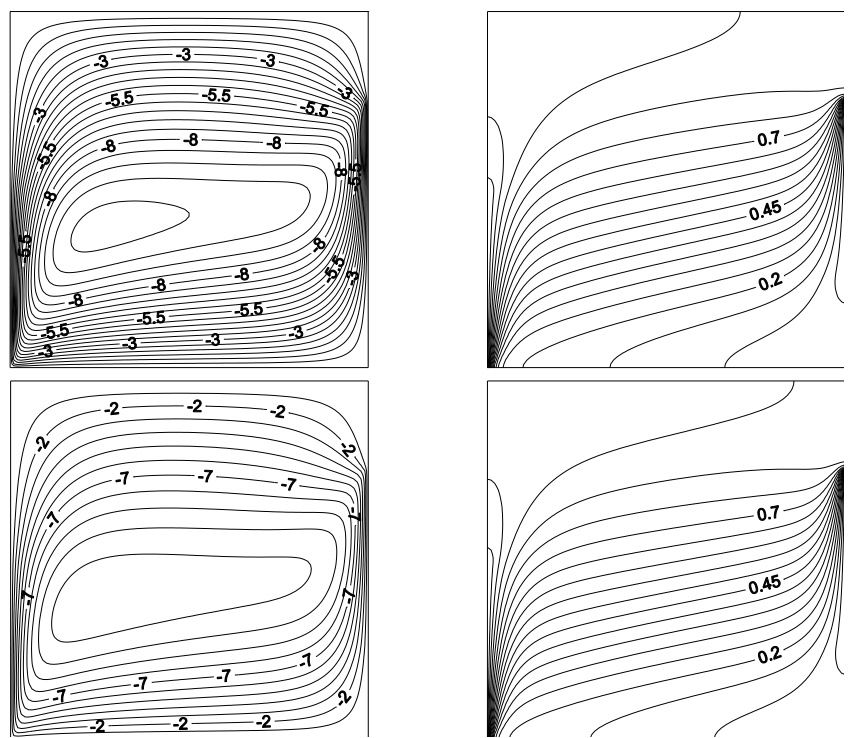

Figure (7) Effect of Rayleigh number for the case ( Lower - Central ).

(a)
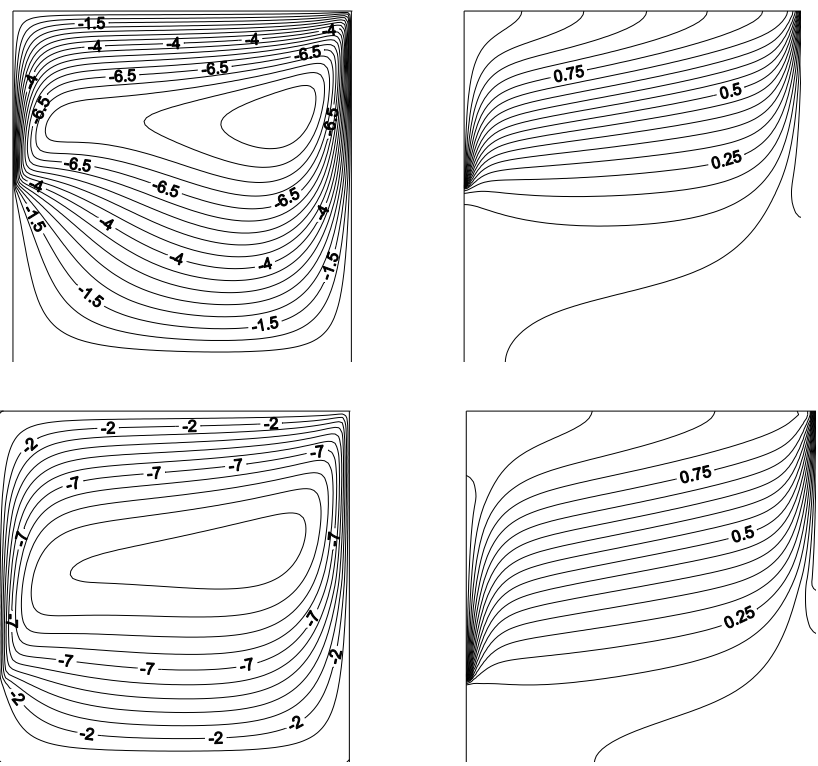

(b)
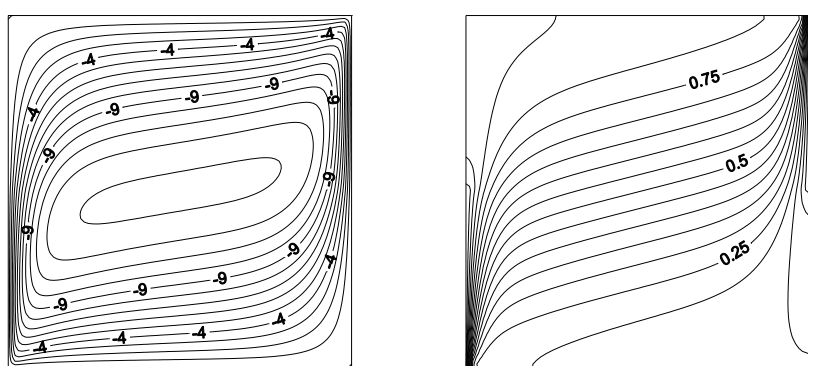

Figure (8) isotherm and streamlines for different cases : (a) Upper - Upper , (b) Central Upper, and (c) Lower - Upper thermally active locations. 
Figure (9) shows the variation of the rate of heat transfer represented by average Nusselt number $(\overline{\mathrm{Nu}})$ with variation of Rayleigh number $\left(\mathrm{Ra}_{\mathrm{m}}\right)$ for different cases. The case of changing the hot portion from up to down on the left wall with fixing the position of the cold portion at the lower part of the right wall is illustrated in Figure (9-a). It is clear that the average Nusselt number $(\overline{\mathrm{Nu}})$ increases with increasing the Rayleigh number. Furthermore, changing the position of the hot portion leads to changing the values of Nusselt number. For a given value of Rayleigh number, $\mathrm{Ra}_{\mathrm{m}}=300$, Nusselt number has a minimum value for the case Upper - Lower thermally active location and a maximum value for the case Lower Lower thermally active location. The same behavior occurs for the rest of the cases as shown in Figure (9 - b and $c)$.

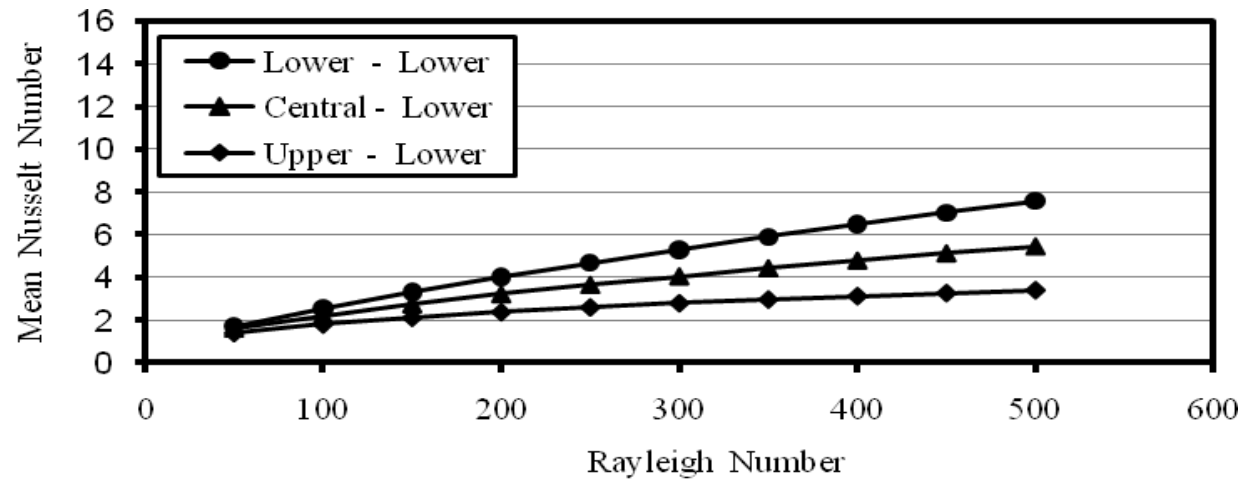

(a)

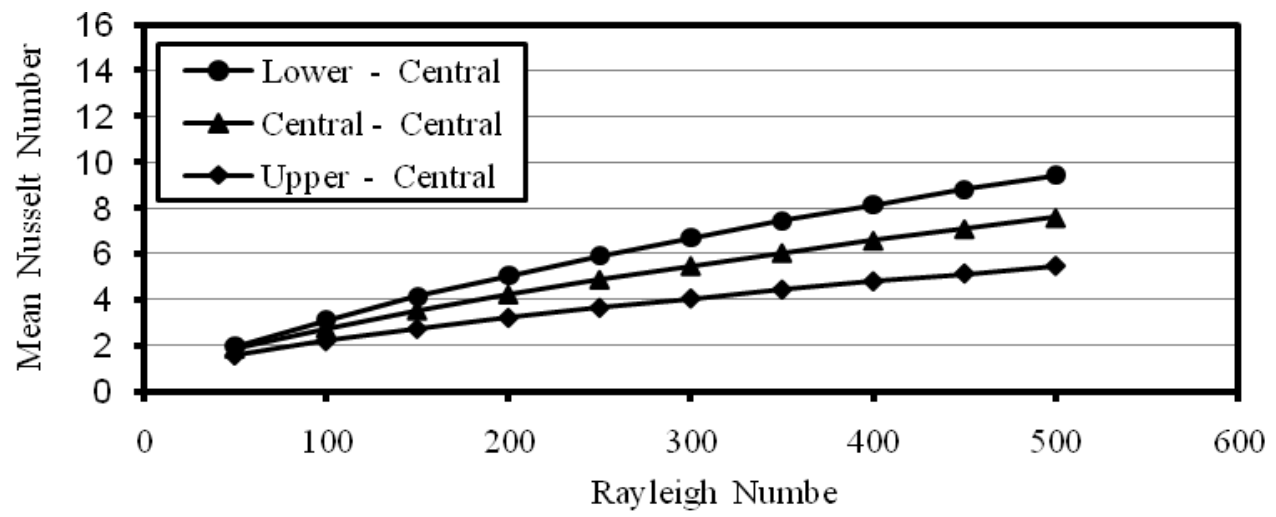

(b)

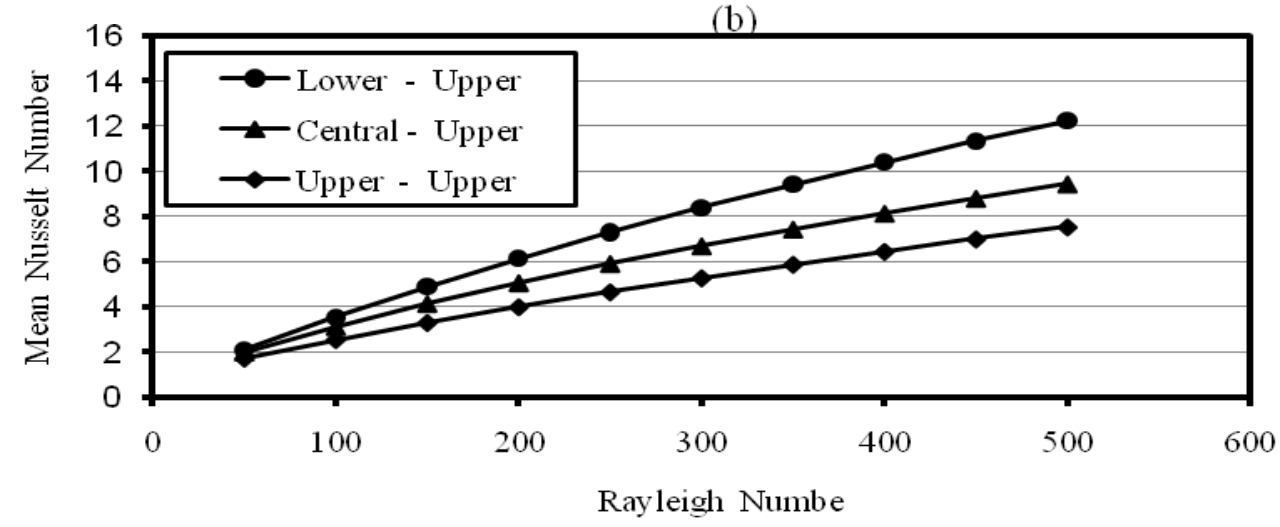

(c)

Figure (9) Variation of Nusselt number with Rayleigh number for all cases under study. 
Figure (10) depicted the variation of average Nusselt number $(\overline{\mathrm{Nu}})$ with Rayleigh number $\left(\mathrm{Ra}_{\mathrm{m}}\right)$ for the case of lower heating and the cold portion changed from up to down. The maximum rate of heat transfer takes place when the arrangement is Lower - Upper thermally location because the convection mode is very strong. On the other hand, the variation of average Nusselt number $(\overline{\mathrm{Nu}})$ with Rayleigh number $\left(\mathrm{Ra}_{\mathrm{m}}\right)$ for the case of upper heating and the cold portion changed from up to down is shown in Figure (11). It is obvious that the minimum rate of heat transfer takes place when the arrangement is Upper - Lower thermally active location. Table (3) shows a summary of the results for all cases under study.

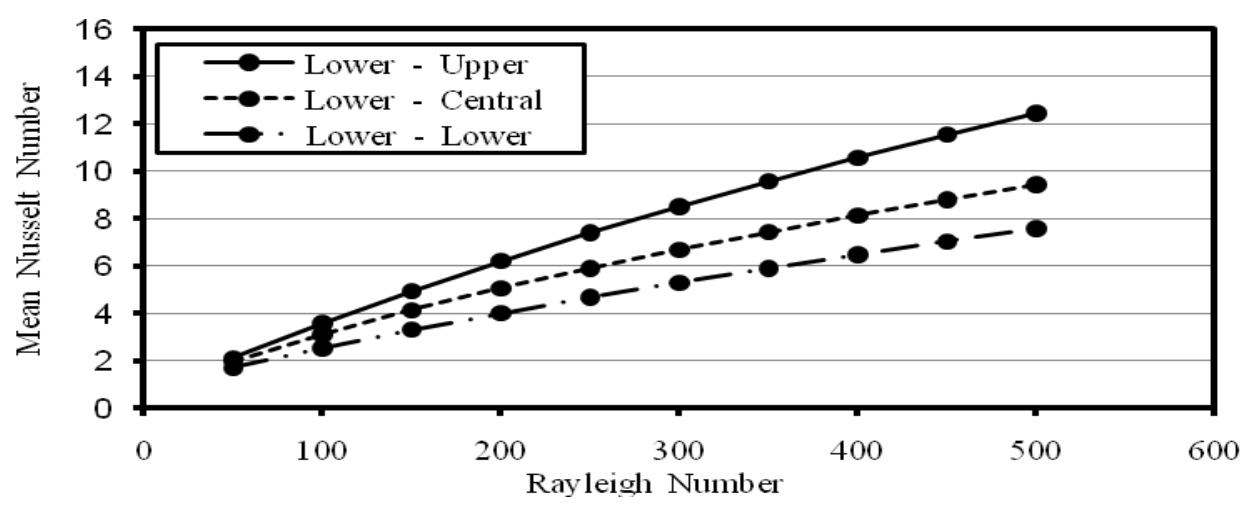

Figure (10) Variation of Nusselt number $(\overline{\mathrm{Nu}})$ with Rayleigh number $\left(\mathrm{Ra}_{\mathrm{m}}\right)$ for the case of lower heating on the left side wall with different positions of cooling on the right side wall.

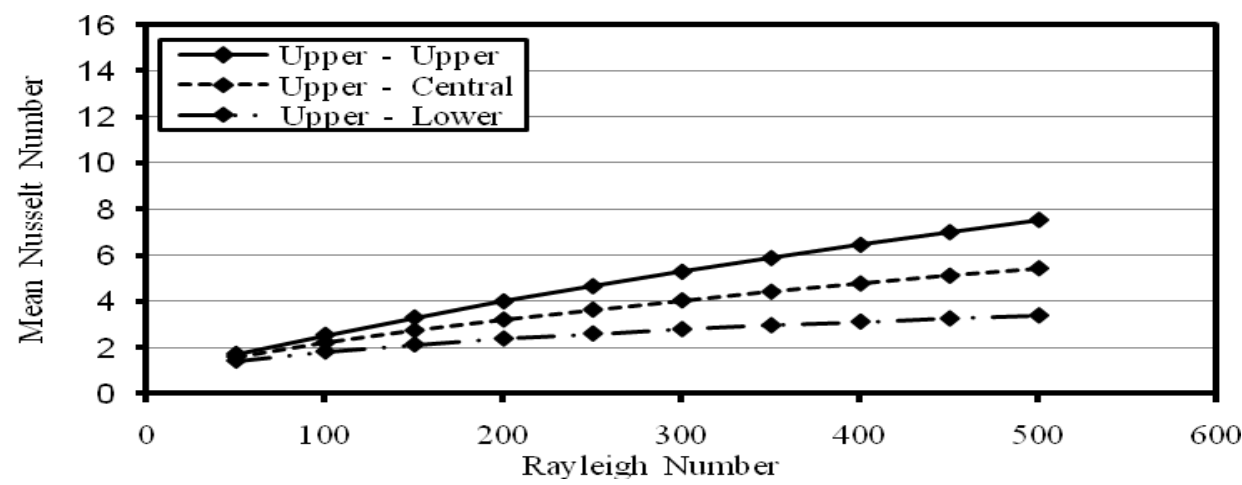

Figure (11) Variation of Nusselt number $(\overline{\mathrm{Nu}})$ with Rayleigh number $\left(\mathrm{Ra}_{\mathrm{m}}\right)$ for the case of upper heating on the left side wall with different positions of cooling on the right side wall.

A relationship correlating the rate of heat transfer $(\overline{\mathrm{Nu}})$ and Rayleigh number $\left(\mathrm{Ra}_{\mathrm{m}}\right)$ is represented by the following equation :

$$
\overline{\mathrm{Nu}}=\mathrm{a}\left(\mathrm{Ra}_{\mathrm{m}}\right)^{\mathrm{b}}
$$

where $\mathrm{a}$ and $\mathrm{b}$ are constants listed in Table(4). 
Table (3) summary of the results for all cases under study.

\begin{tabular}{|l|c|c|c|c|}
\hline & Case & & $\overline{\mathrm{Nu}}$ & Notices \\
\hline Upper & - & Lower & $1.412 \leq \overline{\mathrm{Nu}} \leq 3.383$ & Minimum heat transfer \\
\hline Central & - & Lower & $1.595 \leq \overline{\mathrm{Nu}} \leq 5.451$ & \\
\hline Lower & - & Lower & $1.71 \leq \overline{\mathrm{Nu}} \leq 7.573$ & \\
\hline Upper & - & Central & $1.588 \leq \overline{\mathrm{Nu}} \leq 5.446$ & \\
\hline Central & - & Central & $1.84 \leq \overline{\mathrm{Nu}} \leq 7.577$ & \\
\hline Lower & - & Central & $1.969 \leq \overline{\mathrm{Nu}} \leq 9.438$ & \\
\hline Upper & - & Upper & $1.704 \leq \overline{\mathrm{Nu}} \leq 7.544$ & \\
\hline Central & - & Upper & $1.968 \leq \overline{\mathrm{Nu}} \leq 9.436$ & \\
\hline Lower & - & Upper & $2.097 \leq \overline{\mathrm{Nu}} \leq 12.255$ & Maximum heat transfer \\
\hline
\end{tabular}

Table (4) Constants of equation (8) for all cases.

\begin{tabular}{|c|c|c|c|c|}
\hline \multicolumn{2}{|c}{} & \multicolumn{2}{c|}{ Constants } \\
\cline { 3 - 5 } \multicolumn{2}{|c|}{} & a & $\mathrm{b}$ \\
\hline Upper & - & Lower & 0.311 & 0.384 \\
\hline Central & - & Lower & 0.172 & 0.546 \\
\hline Lower & - & Lower & 0.128 & 0.654 \\
\hline Upper & - & Central & 0.185 & 0.542 \\
\hline Central & - & Central & 0.160 & 0.620 \\
\hline Lower & - & Central & 0.135 & 0.684 \\
\hline Upper & - & Upper & 0.127 & 0.654 \\
\hline Central & - & Upper & 0.134 & 0.685 \\
\hline Lower & - & Upper & 0.103 & 0.770 \\
\hline
\end{tabular}

\section{Conclusions}

Numerical investigation is conducted to study the effect of partially heating cooling on natural convection in a square cavity. Effects of Rayleigh number and arrangements of hot - cold portion were chosen as governing parameters. It was observed that:

1. The arrangements of active portions play an important role on flow, temperature fields and heat transfer. 
2. The highest heat transfer was obtained for the Lower - Upper arrangement.

3. The lowest heat transfer was obtained for the Upper - Lower arrangement.

4. Also, heat transfer increases with the increasing of Rayleigh number for all cases.

5. The same behavior is noticed for a cavity containing fluid only.

\section{REFERENCES}

1. Lai, F. C., Kulacki, F. A., "Natural convection across a vertical layered porous cavity," Int. J. Heat Mass Transfer, 31, 1988, pp.1247-1260.

2. Varol, Y., Oztop, H., and Avci, E." Estimation pf thermal and flow fields due to natural convection using support vector machines ( SVM ) in a porous cavity with discrete heat sources," Int. com. Heat Mass Transfer, 35, 2008, pp.928-936.

3. Bejan A., Poulkakos D. ," Natural convection in porous layer heated and cooled along one vertical side," Int. J. Heat Mass Transfer, 27, 1984, pp.1879-1891.

4. Varol, Y., Oztop, H., Pop, I.," Natural convection in right -angle porous trapezoidal enclosure partially cooled from inclined wall," Int. com. Heat Mass Transfer, 36, 2009, pp.6 - 15 .

5. Frederick, R., Valencia, A.," Heat transfer in a square cavities with Partially active vertical walls," Int. J. Heat Mass Transfer, 32, 1989, pp.1567-1574.

6. Aydin, O., Yang, W.," Natural convection in enclosures with localized heating from below and symmetrical cooling from sides." Int. J. Num. Meth. Heat Fluid Flow, 10, 2000, pp.518 - 529.

7. Erbay, L.,B., Altac, Z., Sulus, B.," Entropy generation in a square enclosure with partial heating from a vertical lateral wall," J. Heat Mass Transfer, 40, 2004, pp.909 - 918.

8. Nithyddevi, N., Kandaswamy , P., Lee , J., " Natural convection in a rectangular cavity with partially active side walls,” Int. J. Heat Mass Transfer, 50, 2007, pp.4688 - 4697.

9. Koca, A., Oztop, H., Varol, Y.," The effect of Prandtl number on natural convection in triangular enclosures with localized heating from below," Int. com. Heat Mass Transfer, 34, 2007, pp.511 - 519.

10. Oztop, H., Abu-Nada, E.," Numerical study of natural convection in partially heated rectangular enclosures filled with nanofluids.” Int. J. Heat Fluid Flow, 29, 2008, pp.1326 $-1336$.

11. Dawood, A. S., Ismaeel, M. E.," Numerical study of natural convection in an inclined square porous layer," AL-Rafidain Engineering, 16, 2008, pp.81-95.

12. Varol, Y., Oztop, H., Pop, I.," Numerical analysis of natural convection for a porous rectangular enclosure with sinusoidally varying temperature profile on the bottom wall," Int. com. Heat Mass Transfer, 35, 2008, pp.56 - 64.

13. Chan, B. K., Ivey, C. M. and Barry, J. M.," Natural convection in enclosed porous media with rectangular boundaries," J. Heat Transfer, 2, 1970, pp. $21-27$,

14. Bejan, A., "Natural convection heat transfer in a porous layer with internal flow obstruction," Int. J. Heat Mass Transfer, 26, 1983, pp.815 - 822.

15. Bejan, A., and Tien, C. L., "Natural convection in a horizontal porous medium subjected to an end-to-end temperature difference," J. Heat Transfer, 100, 1978, pp.191 - 198.

The work was carried out at the college of Engineering. University of Mosul 